\title{
EFFECT OF CLIMATIC ACTIONS ON BUILDINGS WITH INTERNAL INSULATION AND THERMAL BREAKS : MULTI-SCALE APPROACH AND THERMO-HYDRO-MECHANICAL MODELING
}

\author{
Try Meng ${ }^{1, *}$, Hugues Somja ${ }^{1}$, Fekri Meftah ${ }^{1}$ and Piseth Heng ${ }^{1,2}$, \\ ${ }^{1}$ Institut National des Sciences Appliquées de Rennes, Laboratoire de Génie Civil et Génie Mécanique \\ (Equipe GEOSAX) \\ 20 Avenue des Buttes de Coësmes, CS 70839, F-35708, Rennes, France \\ * corresponding author, email: try.meng@insa-rennes.fr \\ ${ }^{2}$ INGENOVA, Civil Engineering office \\ Rennes, France
}

Key words: Thermal break, thermal dilatation, restraint, crack, thermo-hydro-mechanical analysis

\begin{abstract}
For buildings designed with internal insulation, thermal bridges at the junction between slabs and walls are a common issue, since they create heat loss from inside of the building. Thermal break systems (TBS), which are composed of structural elements (rebars and steel profiles) and insulation material, are used to reduce this heat loss and to transfer shear forces from the slab to the walls. Insulation system of TBS generates a temperature gap from wall to slab. As a consequence, while the wall is exposed to climatic actions and is repeatedly dilated and contracted, whereas the slab pertains a constant temperature and does not present any volumetric variation, thus the TBSs are submitted to large displacement constrains. The paper illustrates the effect of the thermal dilatation and contraction of the walls, which create a supplemental force in the TBSs, and consequently cracking of the walls. A numerical model of a quarter of a building's storey is submitted to the climatic actions computed at the location of Embrun city, in France. One side of the L-shape wall is supposed to face to the south, and the other one to the west. The thermal and mechanical analysis are performed with the software CASTEM. In thermal analysis, air temperature and flux of solar radiation signal are defined from databases of METEO FRANCE, and are applied on the exterior surface of the walls. The results of the first calculation, by thermo-hydro-mechanical analysis (THM) with elasticity behavior, confirm that a significant stress level in tension occurs in the concrete at the corner of the walls and the nearby interface elements of the TBS. Furthermore, the TBSs that are close to the corner of the walls pertain the highest horizontal and axial forces, and are at risk to exceed the limit strength. Based on those results, a second calculation, which includes the coupling of damage with shrinkage and creep model from the THM analysis, is made for determining more realistic forces in the TBSs, and analyzing the cracking pattern of the walls.
\end{abstract}

\section{INTRODUCTION}

In Europe, reduction of energy consumption for residential building has been initially raised in the directive on energy performance in building in 2002. Among the sources of heat loss, thermal bridges, which are caused by the discontinuity of the insulation system at the interface of the slab to the wall or the slab to the balcony, are known as a common issue for creating a path for heat loss. Thermal break systems (TBS) mean to solve this problem while ensuring the transfer of the load. The TBS is thus composed of insulation and structural elements, see [Figs. 1a and 1b]. 
In spite of its thermal benefits, the existence of TBS also generates a temperature gap, which separates the temperature field from the wall to the slab in the case of internal insulation. The thermal expansion and contraction of the wall due to the thermal behavior of the concrete under the climatic actions are constrained by the slab side. The displacement constraints of the wall are then believed to create supplemental forces in the TBSs, and also in the nearby concrete structures. Those forces may be large enough to provoke some damage in the TBS, and the cracking of the surrounding concrete. The study presented in this paper tries to give a first scientific insight on those phenomenons. The problem can only be solved realistically by a refined modeling that takes into account the climatic action, the non linear behavior of the TBS and the strain softening of the concrete. Moreover, as climatic actions are considered as long term actions, creep and shrinkage effects are also included.

To the best of the author's knowledge, a thermo-mechanical simulation of buildings with internal insulation and equipped with TBS has never been presented before in the literature. In this paper, a numerical simulation based on finite element method and multi-scale approach is developed. The multiscale approach includes the numerical modeling of the structural elements such as: wall, slab and TBSs. Besides that, refined modelings of the material behavior : drying shrinkage [1-3], creep [4], damage elasticity of concrete [5] and elasto-plasticity of TBS [6,7] are considered as second part of the multi-scale approach. Once the numerical and material modelings are developed and implanted in CASTEM [8], the full numerical simulation of a building scale is launched, and serves as a tool for analyzing stress, displacement and damage distribution in the walls, and supplemental forces that happen in TBSs. The simulation initially starts with the thermal and hydro analysis, where the imposed signal of

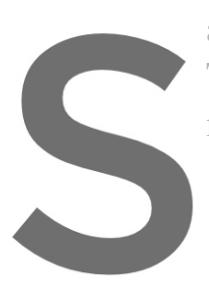
air temperature, solar ra The temperature and hu mechanical analysis of

(1)

Register for free at https//Whatw.scipedia.com to do

$\varnothing 10$ bars
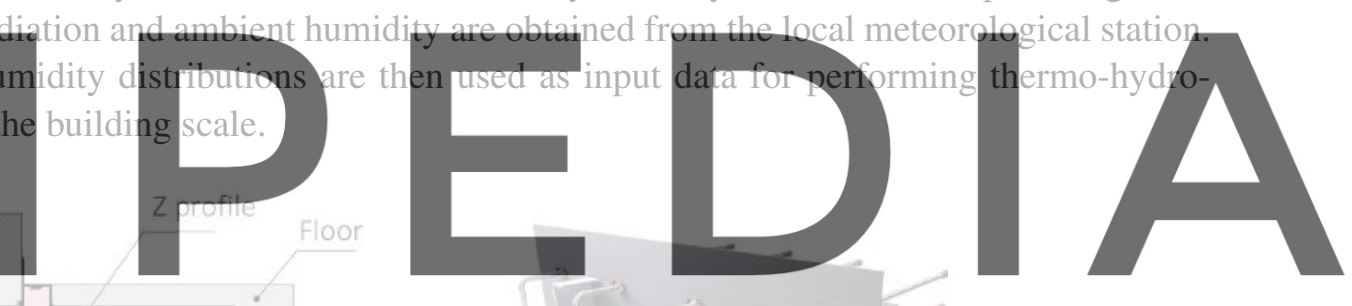

(a)

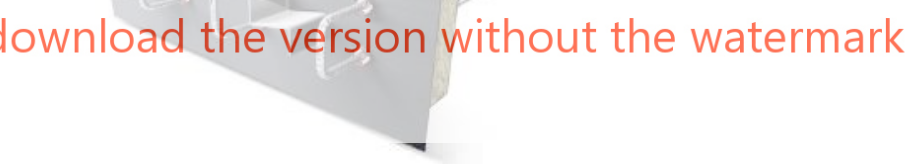

(b)

Figure 1: (a) geometry of TBS connected between slab and wall, (b) TBS (SLABE ZN ${ }^{\circledR}$ )

\section{CLIMATIC ACTIONS}

As mentioned in Section 1, the principal loading in the simulation is the thermal loading, which is defined by the combination of air temperature and solar radiation signal. Besides that, to include the shrinkage effect, the shrinkage strains are calculated from the relative humidity of concrete, then the hydric analysis based on the imposed humidity is necessary. Those signals are obtained from the database of METEO FRANCE [9], and will be presented in this section.

\subsection{Temperature signal generation}

The temperature signal used in thermal analysis is constructed base on the maximum and minimum temperature of each day. The maximum and minimum of temperature and time of occurrence are those of the meteorological station located at Embrun city in France. The daily air temperature signal [Fig. 2] 
is simplified to a sinusoidal signal, see Eq. (1). $T_{\max }$ and $T_{\min }$ are corresponding to the maximum and minimum daily temperature, whereas $t_{\max }$ and $t_{\min }$ are time corresponding to $T_{\max }$ and $T_{\min }$, respectively.

$$
T(t)=T_{\min }+\frac{T_{\max }-T_{\min }}{2}\left[1-\cos \left(\pi \frac{t-t_{\min }}{t_{\max }-t_{\min }}\right)\right]
$$

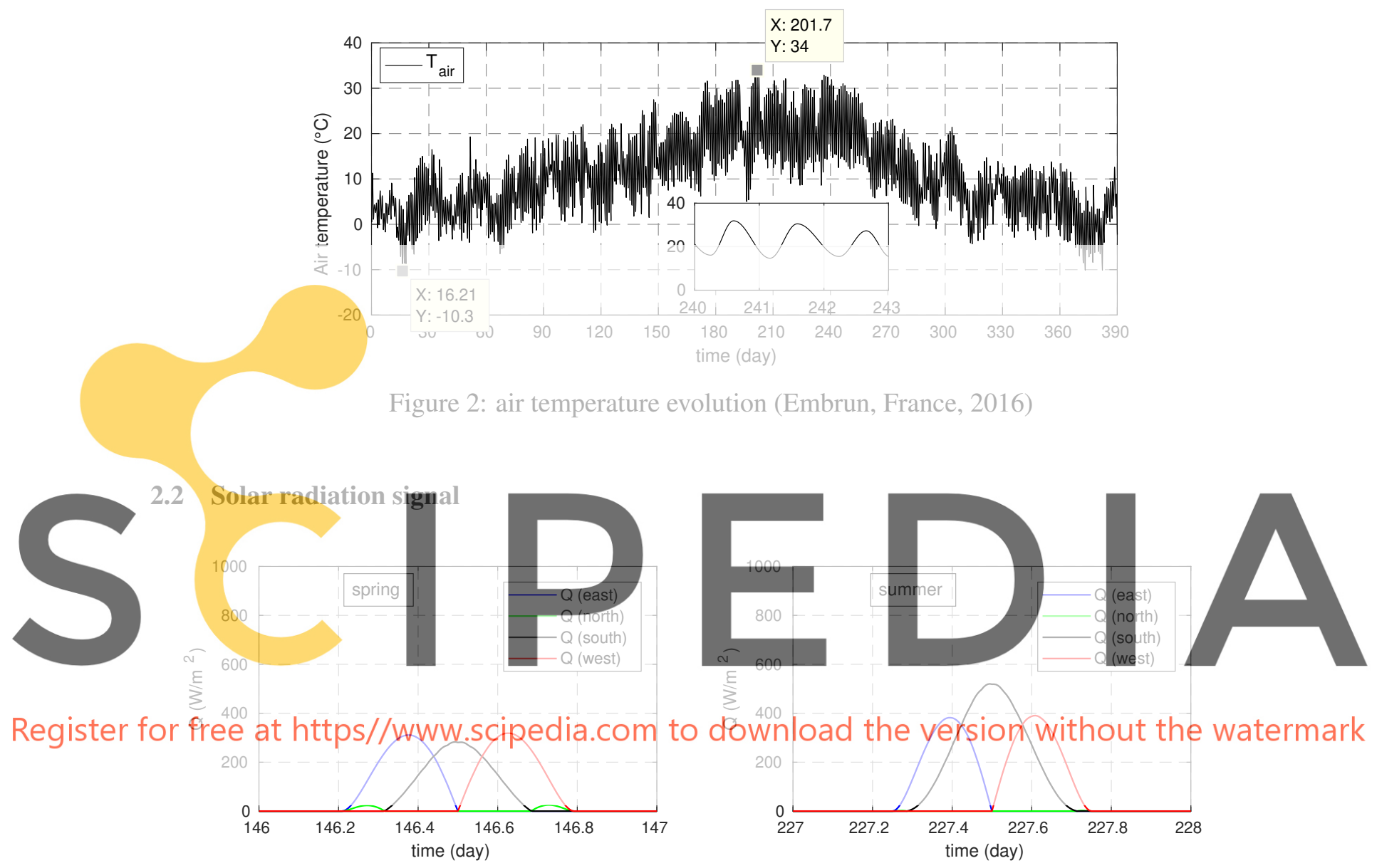

Figure 3: daily solar radiation evolution for different orientations and seasons $\left(\varepsilon_{s}=0.7\right)$

The pure data, global solar radiation, is projected on vertical surfaces with different orientations (south and west), see in [Fig. 3]. Furthermore, the color effect of the building is taken into account by the coefficient emissivity $\left(\varepsilon_{s}\right)$, in which 0.7 for the light colored surface, see Tabel 5.2 of EN 1991-1-5 [10].

\subsection{Ambient humidity signal}

The ambient humidity signal is also obtained from the database of METEO FRANCE [9], the data are monthly average humidity, see [Fig. 4]. This signal is used in hydric analysis, and is applied on the exterior surface of the walls, while the interior environment, a constant humidity of $60 \%$ is considered.

\section{THERMAL ANALYSIS}

The thermal analysis is performed by CASTEM [8], which is based on the finite elements method. The double complexities, including non linear behavior of the materials and large scale of finite elements structure and types of the elements, the numerical model is reduced to a quarter of a storey of a building 


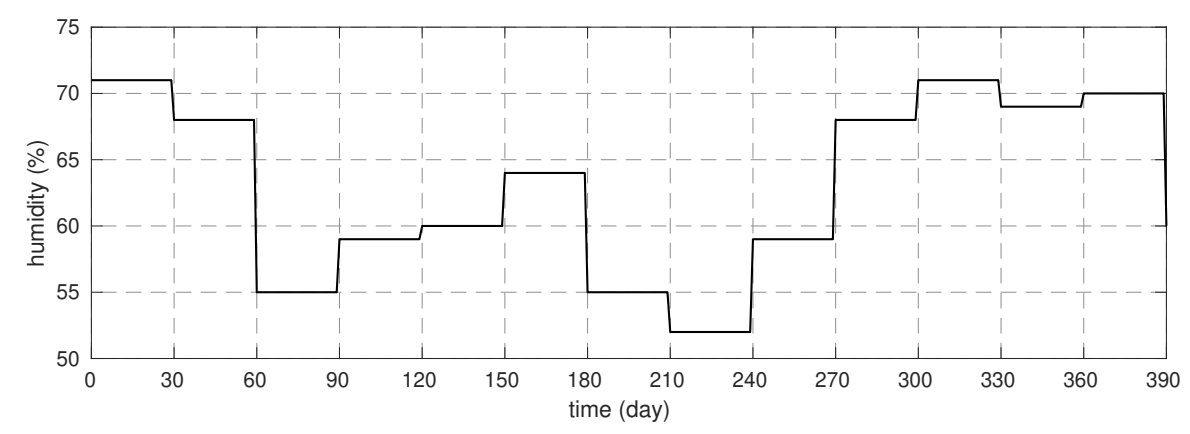

Figure 4: ambient humidity evolution, monthly average (Embrun, France, 2016)

(L shape walls), see [Fig. 5]. It is supposed that the building is symmetry, and the floor a constant temperature, as a consequence, the floor is omitted for thermal modeling. The long and short walls are exposed to the most critical directions, south and west.
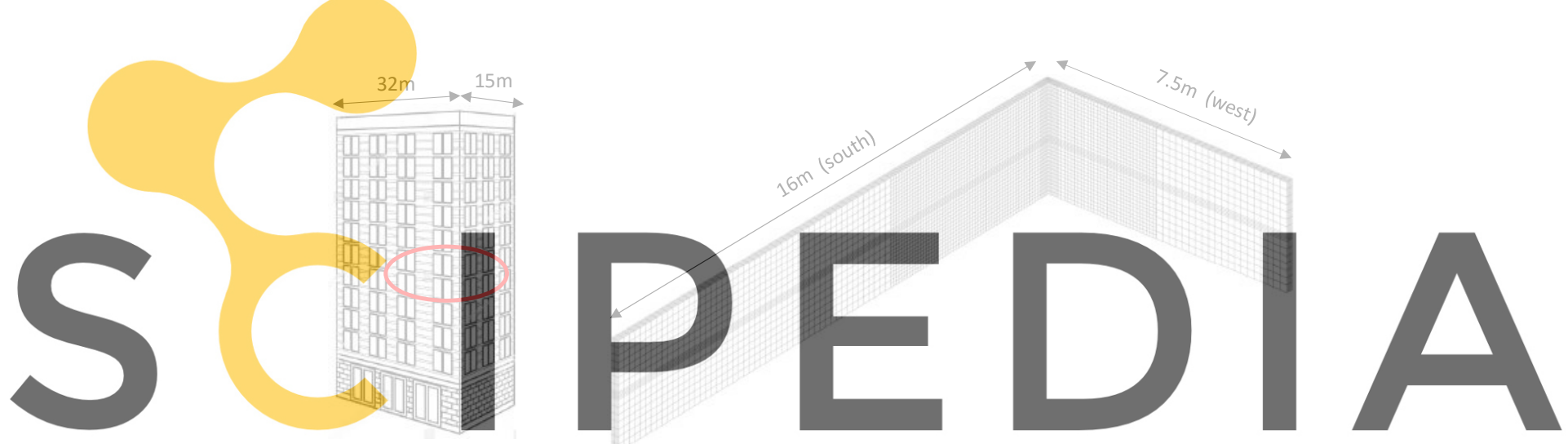

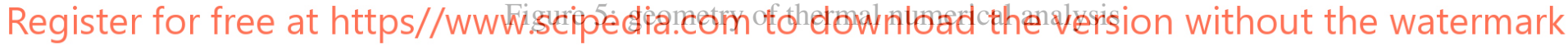

\subsection{Thermal equations}

Thermal analysis in this paper is governed by the conventional heat equation :

$$
\rho C_{p} \dot{T}-\operatorname{div}(\lambda \cdot \overrightarrow{\operatorname{grad}} T)-q_{v}=0
$$

with the law of Fourier :

$$
\vec{q}(x)=-\lambda \cdot \overrightarrow{\operatorname{grad}} T
$$

and boundary conditions :

$$
\vec{n} \cdot(\lambda \cdot \overrightarrow{\operatorname{grand}} T)=\varphi_{s}+h\left(T_{f}-T\right)
$$

The thermal properties of the concrete that are considered in thermal analysis are presented in Table 1:

\begin{tabular}{|c|c|c|}
\hline$\lambda(\mathrm{W} / \mathrm{m} \cdot \mathrm{K})$ & $C_{p}(\mathrm{~J} / \mathrm{Kg} \cdot \mathrm{K})$ & $\rho\left(\mathrm{Kg} \cdot \mathrm{m}^{-3}\right)$ \\
\hline 1.75 & 900 & 2500 \\
\hline
\end{tabular}

Table 1: thermal properties of concrete 


\subsection{Boundary condition}

The signal of solar radiation is applied directly on the exterior surface of the walls, whereas the air temperature signal is exposed to the wall by the flux of convection. Moreover, to simplify the numerical simulation in thermal analysis, the layers of insulation material is not modeled, but an equivalent thermal transmittance is considered $\left(h_{e q}\right)$ :

$$
h_{e q}=\frac{1}{R_{s i}+R_{1}+R_{2}+\ldots+R_{s e}}
$$

and $R_{s i}=0.13 ; R_{s e}=0.04 ; R_{i}=d_{i} / \lambda_{i}$

\section{THERMO-HYDRO-MECHANICAL ANALYSIS (THM)}

\subsection{Drying shrinkage modeling}

To include the drying shrinkage strain, the relative humidity distributions are needed, in which the drying model is described by a linear diffusion equation of the second law of Fick :

$$
\frac{\partial H}{\partial t}=\nabla\left[D_{e q}(h) \nabla H\right]
$$

where $D_{e q}\left[m^{2} . s^{-1}\right]$ is the coefficient of diffusion, and depends on the variation of humidity $(\mathrm{H})$. The expression of $D_{e q}(h)$ proposed by [2] (Xi et al. 1994) is adopted:
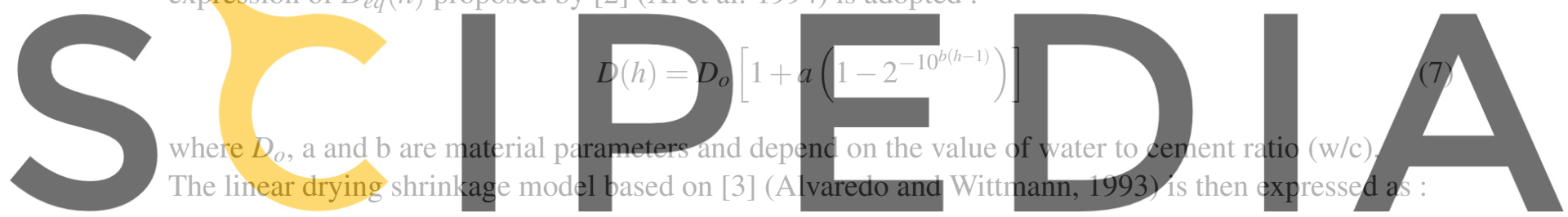

The linear drying shrinkag

\section{$\dot{\varepsilon}_{s h}=K_{s h}^{h} \dot{1}$}

(8)

Register for free at https//www.scipedia.com to download the version without the watermark where, $\dot{\varepsilon}_{s h}$ is the drying shrinkage strain rate vector, $K_{s h}^{h}$ is the hydrous compressibility factor, and $\mathbb{1}$ is the unit vector.

\subsection{Creep modeling}

The creep modeling in this paper is based on the rate type creep law, in which the creep compliance function is the combination of the creep compliance function for basic creep (bc) and drying creep (dc), see Eq. (10). The creep compliance is described by the Kelvin-Voigt model, and the elasticity parameters of the model are identified from creep compliance function curve of Eurocode 2 [Fig. 6]. Aging effect of concrete is also considered into the creep model, as the elasticity parameters are identified at different ages of concrete $\left(t^{\prime}\right)$. The total creep strain is expressed as :

$$
\varepsilon_{\text {creep }}=\int_{0}^{t} J\left(t, t^{\prime}\right) d \sigma\left(t^{\prime}\right)
$$

Both creep compliance functions rely on the Kelvin-Voigt model [Fig. 6], where $J_{b c}$ includes an elasticity spring with 8 units of Kelvin, whereas $J_{d c}$ is only described by 8 units of Kelvin :

$$
\begin{gathered}
J\left(t, t^{\prime}\right)=J_{b c}\left(t, t^{\prime}\right)+J_{d c}\left(t, t^{\prime}\right) \\
J_{b c}\left(t, t^{\prime}\right)=\frac{1}{E_{0}}+\sum_{i=1}^{n} \frac{1}{E_{i, b c}\left(t^{\prime}\right)}\left[1-\exp \left(\frac{\left(t-t^{\prime}\right)}{\tau_{i}}\right)\right] ; J_{d c}\left(t, t^{\prime}\right)=\sum_{i=1}^{n} \frac{1}{E_{i, d c}\left(t^{\prime}\right)}\left[1-\exp \left(\frac{\left(t-t^{\prime}\right)}{\tau_{i}}\right)\right]
\end{gathered}
$$


To consider the influence of relative humidity, the elasticity parameters of basic and drying creep compliance are initially identified from creep compliance of $\mathrm{EC} 2$ at $\mathrm{RH}=95 \%$ and $\mathrm{RH}=30 \%$, respectively. For different relative humidity conditions, those parameters are then modified as :

$$
E_{i, b c}\left(t^{\prime}\right)=\frac{E_{i, b c, 0}}{h} \quad ; \quad E_{i, d c}\left(t^{\prime}\right)=\frac{E_{i, d c, 0}}{\dot{h}}
$$

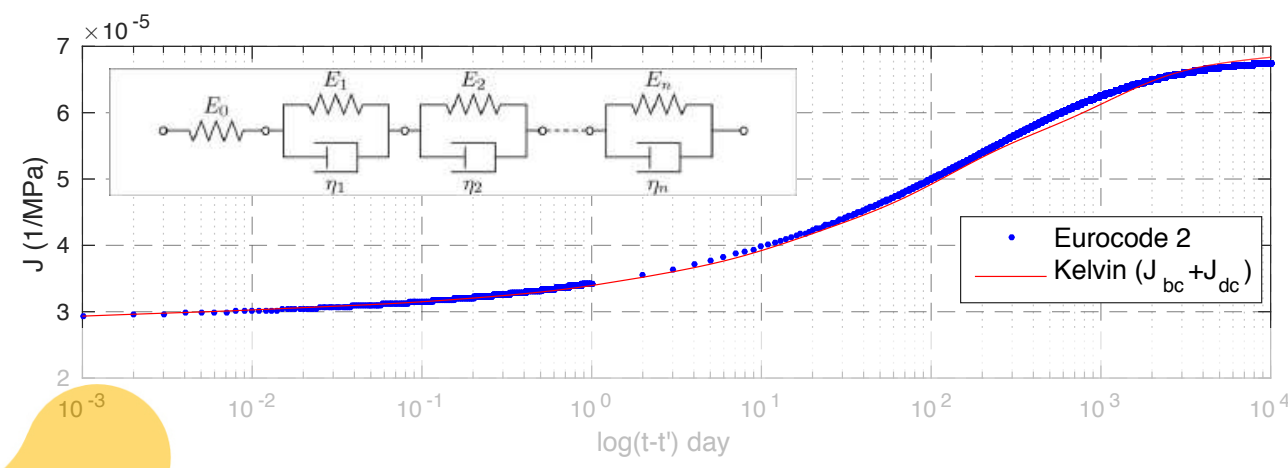

Figure 6: comparison of creep compliance function by Kelvin chain and Eurocode 2 at RH=80\%

4.3 Mechanical model
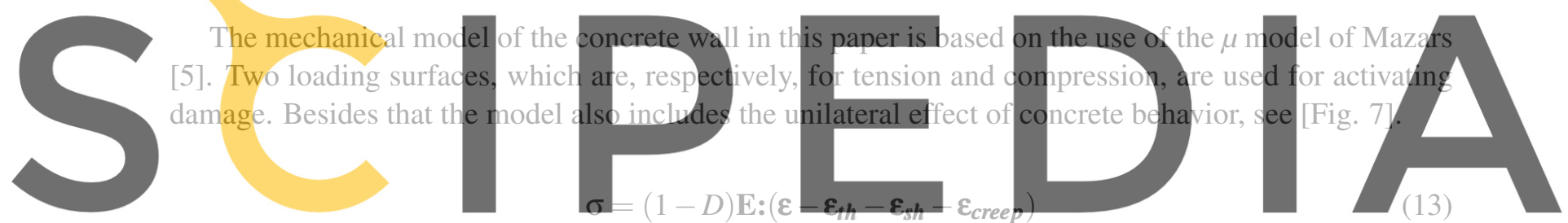

Register for free at https//www,scipjedia.com to download the version without the watermark

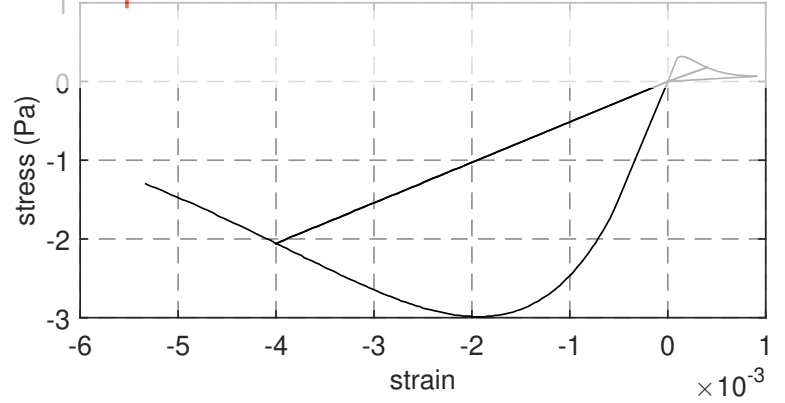

Figure 7: stress-strain curve of concrete based on $\mu$ model

\subsection{Elasto-plasticity model of TBSs}

As TBSs are mainly made of stainless steel, the elasto-plasticity model of TBSs is based on the constitutive law of stainless steel [6], in which the classical laws of kinematic and isotropic hardening are considered. The Helmholtz free energy of the material can be written as a sum of elasticity and inelasticity :

$$
\begin{gathered}
\psi=\rho \psi^{E}+\rho \psi^{I} \\
\rho \psi^{E}=\frac{1}{2} K_{a}\left(U-U_{p}\right)^{2} \quad ; \quad \rho \psi^{I}=\frac{1}{3} C^{p} \alpha_{p}^{2}+R_{\infty}^{p}\left[r^{p}+\frac{1}{b^{p}} \exp \left(-b^{p} r^{p}\right)\right]
\end{gathered}
$$


in which $\alpha_{p}$ and $r^{p}$ are internal variables of kinematic and isotropic plasticity hardening, respectively. $K_{a}$ is the stiffness of the TBS, whereas $C^{p}, R_{\infty}^{p}$ and $b^{p}$ are parameters of the model. The parameters of the elasto-plasticity model have been identified from the result of experiments, that were conducted at the laboratory of LGCGM on a specific TBS (SLABE ZN ${ }^{\circledR}$ ) [Fig. 8a] [11]. As illustrated in [Fig. 8b], the horizontal force-displacement curve of the experiment is compared to the one of the simulation, and the parameters are shown in Table 2 :

\begin{tabular}{|c|c|c|c|c|}
\hline$K_{a}(\mathrm{KN} / \mathrm{m})$ & $C^{p}(\mathrm{MPa})$ & $R_{\infty}^{p}(\mathrm{MPa})$ & $b^{p}$ & $F_{y}(\mathrm{KN})$ \\
\hline 83000 & 130 & 85 & 200 & 87 \\
\hline
\end{tabular}

Table 2: parameters of elasto-plasticity model of TBS

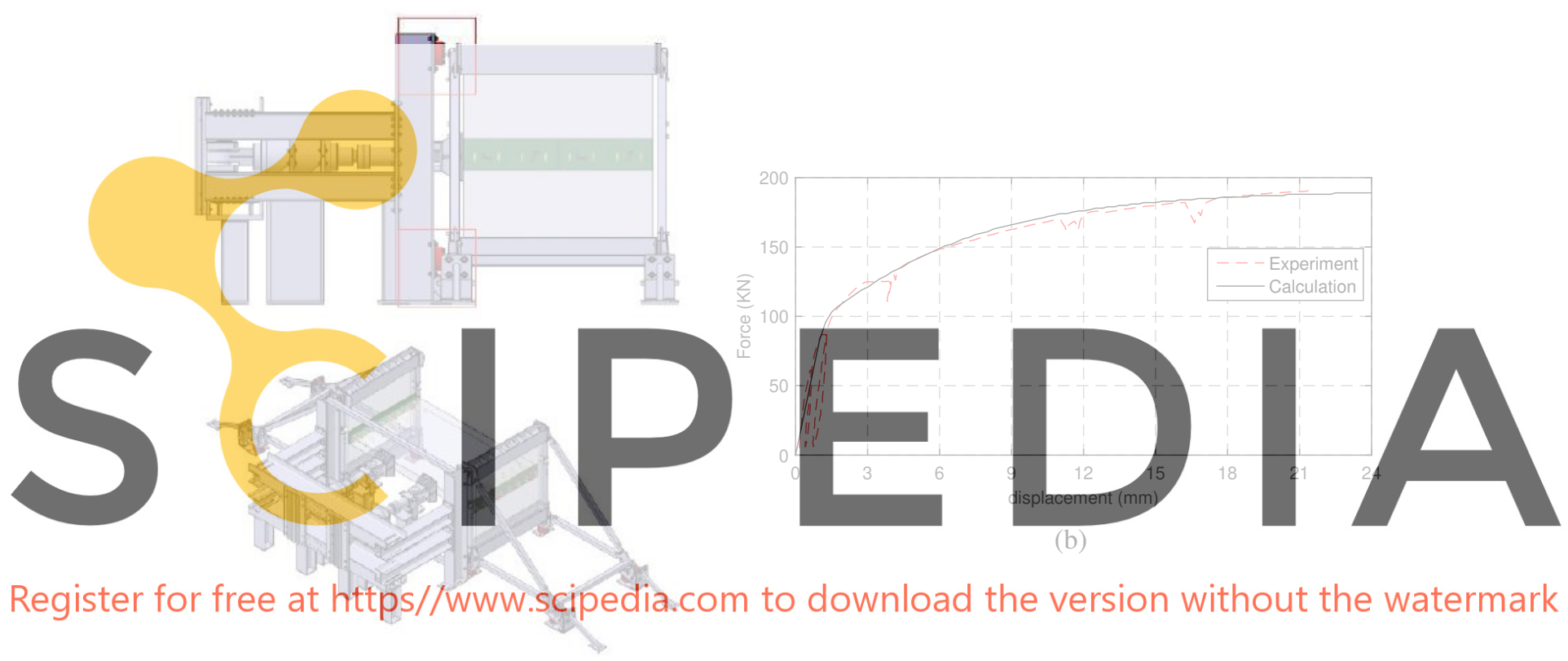

(a)

Figure 8: (a) geometry of specimen and loading position, (b) comparison of horizontal force-displacement curve of the TBS between experiment and simulation

\subsection{Numerical modeling of building scale}

The full numerical simulation in this paper is based on a numerical modeling at building scale [Fig. 9], in which the dimensions of the walls remain the same as the ones of the thermal numerical simulation [Fig. 5]. The wall is modeled by cubic solid elements with 20 nodes, and the slab is placed at the middle height of the wall. A band of the slab with $1 \mathrm{~m}$ width is modeled by cubic solid elements with 8 nodes, and the rest is modeled by 4 nodes shell elements. Regarding to the boundary conditions, the lateral surfaces of the walls and slab are imposed by symmetrical condition, and the top and bottom surface of the walls are imposed to develop the same vertical displacement. Furthermore, to represent the TBS into the numerical modeling, shell elements are added in the wall to represent the reinforcements that are embedded into the concrete wall and slab. A node of the shell elements in the wall is connected to another node of the shell elements in the slab by spring elements [Fig. 9]. The elasto-plasticity model of the TBS discussed in Section 4.4 is applied to these springs. Minimum reinforcements in vertical and 
horizontal directions $\left(A_{v}, A_{h}\right)$ proposed by Eurocode 2 are considered in concrete.
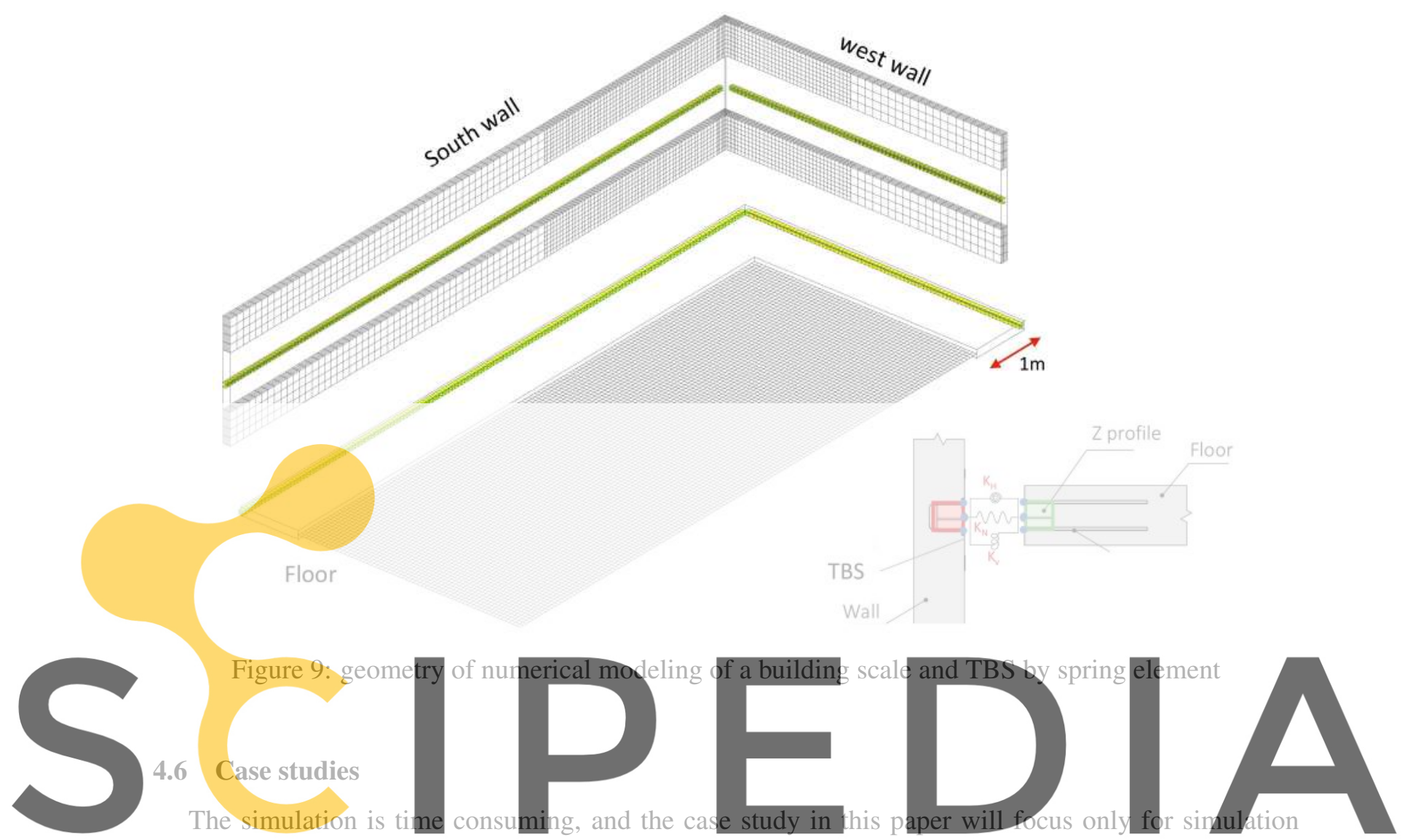

with non linear behavior of the material, see in Table 3. As described in the abstract, with the elastic

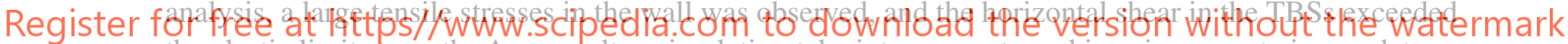
the elastic limit strength. As a result, a simulation take into account crackings in concrete is mandatory.

Furthermore, to avoid of the thermal shock at the beginning of the signals, the mechanical simulation start at t=10.6 days with $T_{r e f}=10^{\circ} \mathrm{C}$.

\begin{tabular}{|c|c|}
\hline linear case & $\begin{array}{c}\text { concrete : THM analysis (elastic behavior); TBS : elasto-plasticity; } 3 \mathrm{MPa} \text { of } \\
\text { loading on the walls; } \varepsilon_{s}=0.7 ; A_{v}=0.27 \% ; A_{h}=0.12 \%\end{array}$ \\
\hline Non linear case & $\begin{array}{c}\text { concrete : THM analysis (elastic damage behavior); TBS : elasto-plasticity; } 3 \\
\text { MPa of loading on the walls; } \varepsilon_{s}=0.7 ; A_{v}=0.27 \% ; A_{h}=0.12 \%\end{array}$ \\
\hline
\end{tabular}

Table 3: summary of case study

\section{RESULTS}

\subsection{Displacement evolution}

The displacement distribution presented in [Fig. 10] is corresponding to the maximum $U_{y}$ at $\mathrm{t}=246.6$ days. The maximum displacement takes place at the corner, and the deformed configuration indicates bending on the west and south wall. In [Fig. 11], the displacement evolutions $\left(U_{x}, U_{y}\right)$ are extracted at the corner of the walls (black dot). Taking into account crackings in concrete, the displacement with elastic damage analysis is almost 2 times larger than the one simulated with elastic behavior. Besides that, several displacement jumps are noticed. These displacement jumps refer to important cracking in 
the walls.

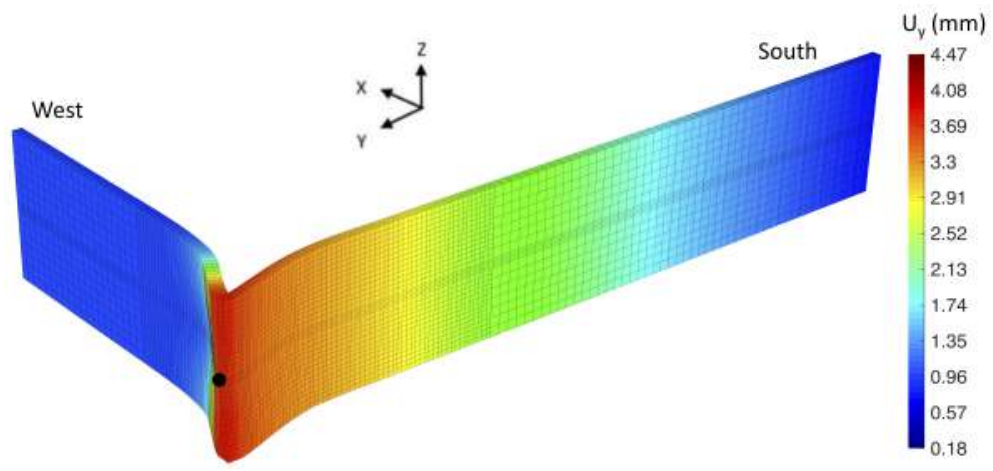

Figure 10: displacement distribution and deformed configuration at $\mathrm{t}=246.6$ days

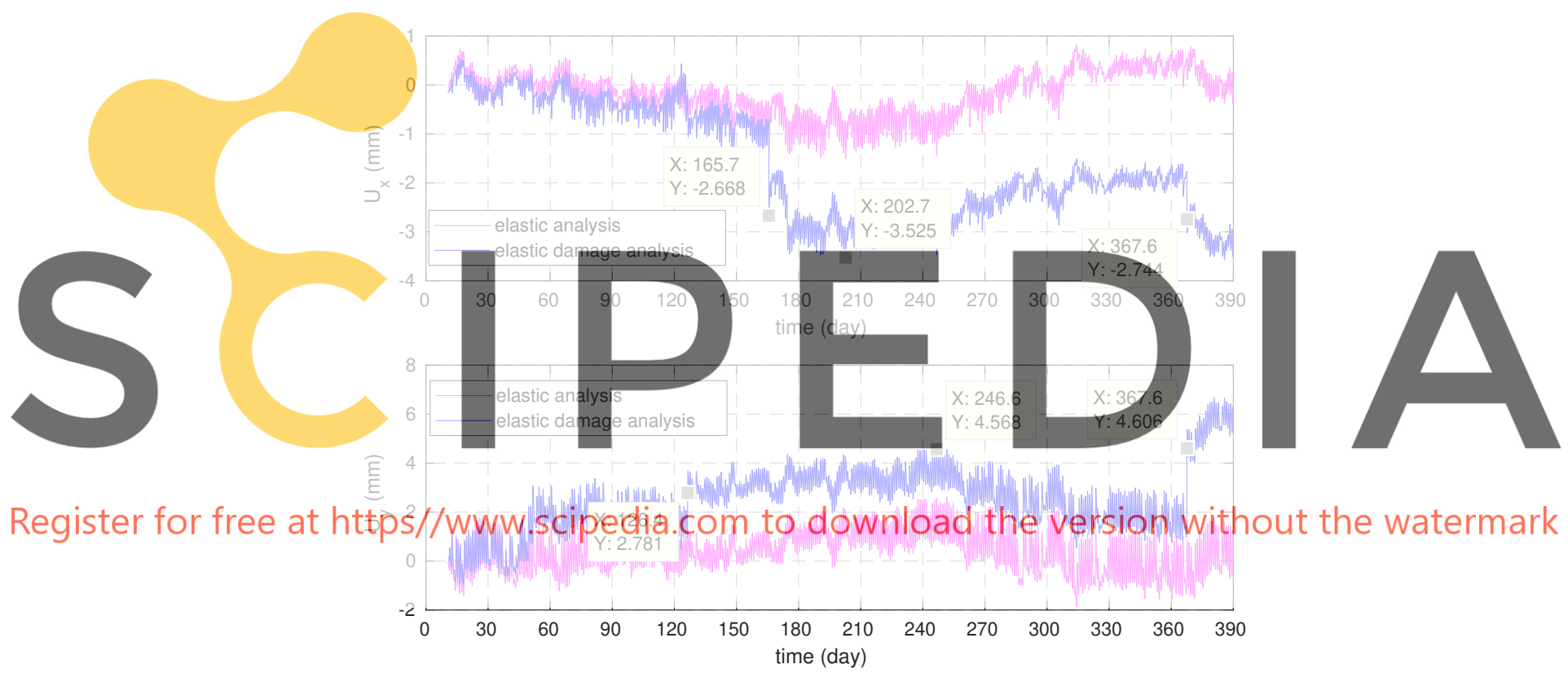

Figure 11: displacement evolutions: (top) $U_{x}$, (bottom) $U_{y}$

\subsection{Damage distribution}

The damage distribution in the walls presented different cracking patterns in the walls, see in Table 4 . As mentioned in Section 4.5, only the minimum reinforcement is applied in the walls, then cracking in the walls is inevitable. These crackings are: cracks at the corner, vertical cracks through the storey and get through the thickness of the walls, crack propagation on the surface and cracking in concrete elements surrounding the TBSs. The displacement jumps described previously is corresponding to those vertical cracks. The vertical cracks on the south are due to the horizontal displacement restraints at the connection wall-slab by the TBSs. Whereas for those on the west locate in the bending zone, and are caused by the dilatation effect from the south wall. The crack propagation on the surface is considered as the shrinkage effect on the skin. 
Try Meng, Hugues Somja, Fekri Meftah and Piseth Heng

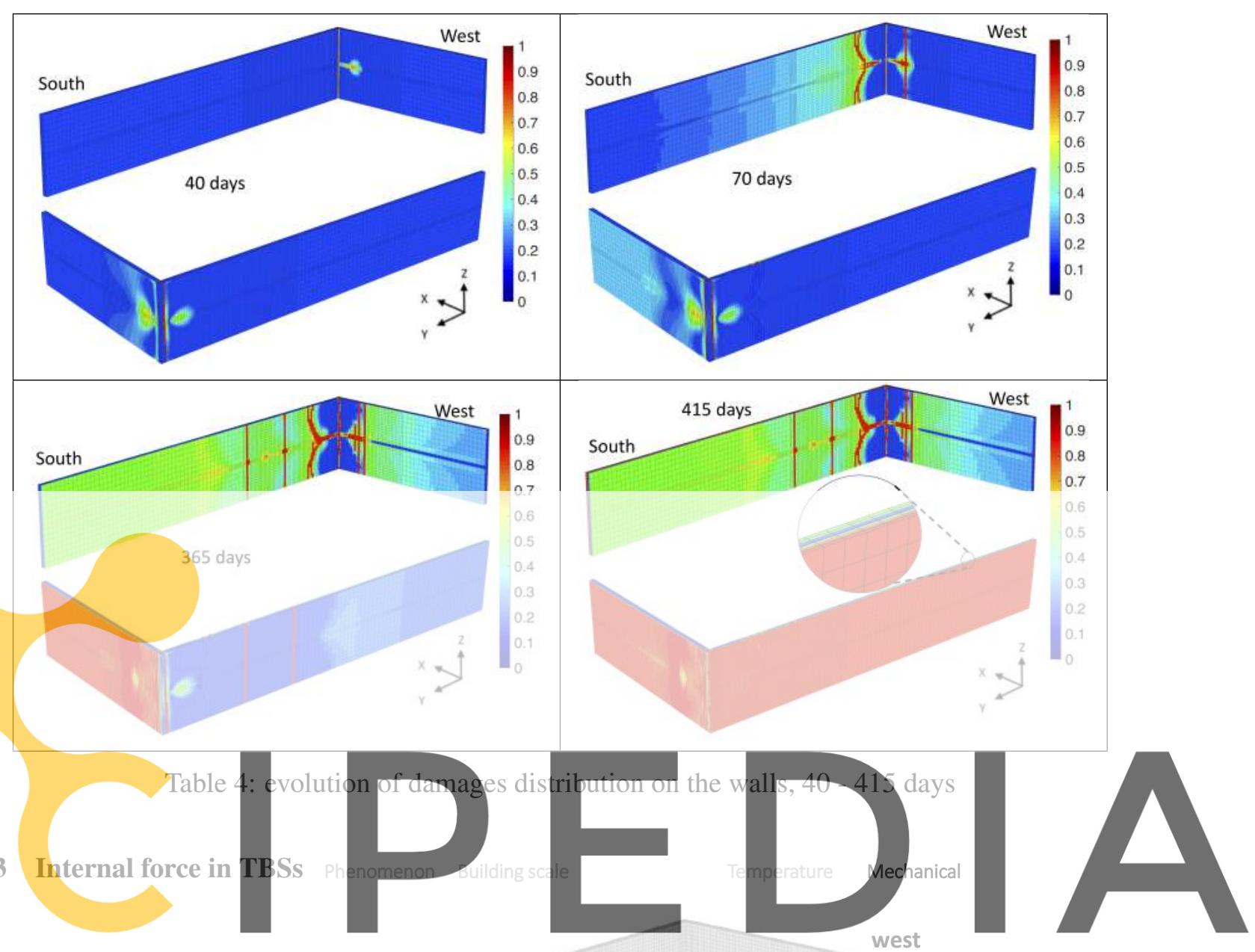

Register for free at https//www.scipedia.com to download the version without the watermark
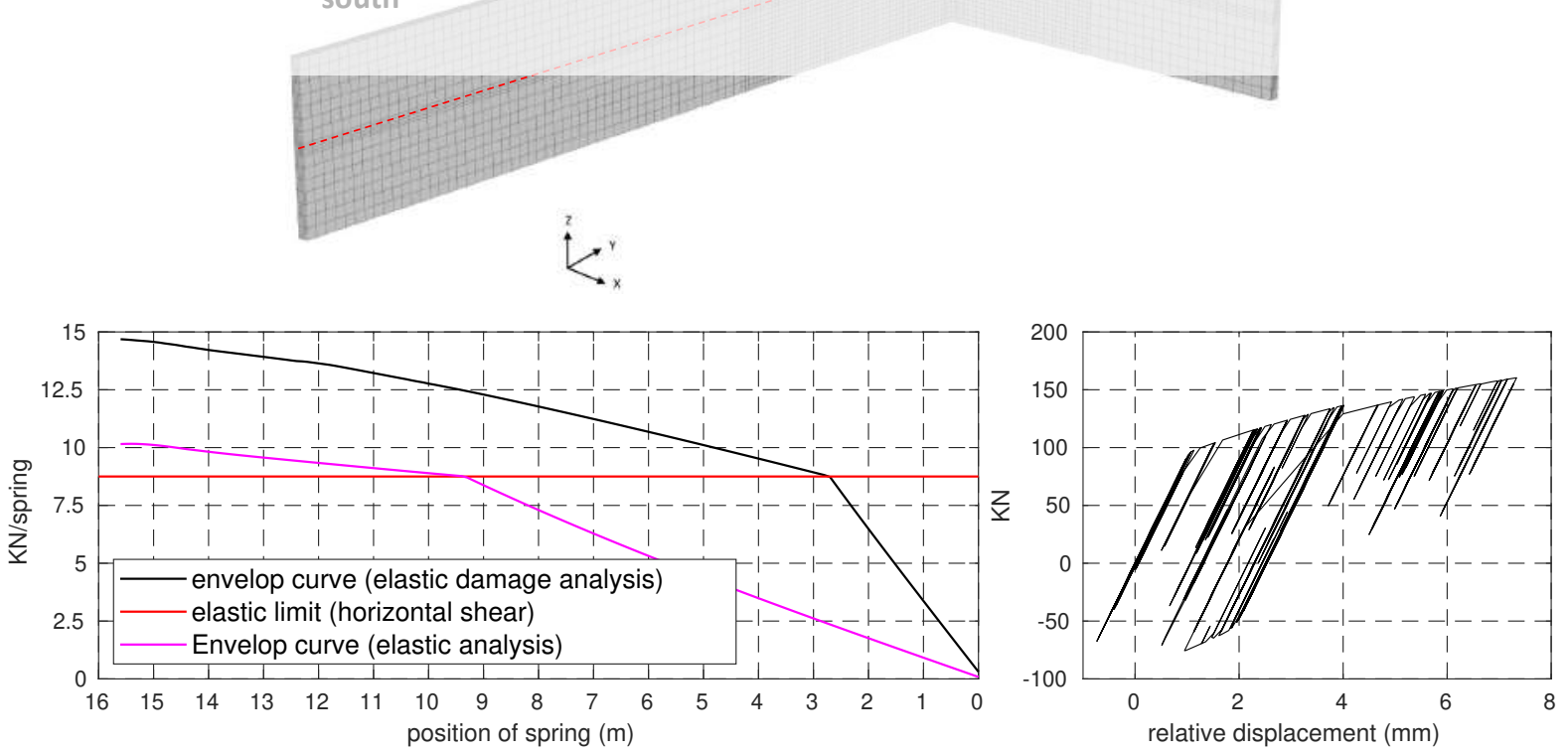

Figure 12: (left): envelop of horizontal shear profiles, (right): shear-displacement of $1^{\text {st }} \mathrm{TBS}$ at the corner 
As described in the displacement evolution, see in Section 5.1, the horizontal displacement of the south wall is important. At here, the envelop curve of shear profiles of the springs implanted on the south wall are depicted in [Fig. 12]. The comparison between the elastic and elastic damage calculations indicated that the number of springs exceeded the elastic limit strength with the elastic damage calculation is twice of the elastic calculation. On the right of [Fig. 12], the shear displacement curve of the $1^{\text {st }}$ TBS at the corner is plotted, and several cycles of horizontal shear get across the elastic limit strength. This observation also mean that the TBSs are concerned by fatigue strength.

In order to understand the order of magnitude of damage in the TBS due to horizontal deformation from the walls, the fatigue analysis is proposed. It should be noticed that the fatigue strength of the TBS here is corresponding to TBS SUNE that is used for the external insulation and at balcony-slab connection [7]. For the one corresponding to the TBS in the simulation is not described by the experiment of low cycle fatigue test. It is known that the fatigue strength of TBS SUNE is lower than the one considered in the simulation. The fatigue analysis is done by counting the amplitude of energy $\left(F_{\max } X_{a}\right)$ through the rainflow approach, see at left of [Fig. 13]. After that the damage accumulation in the TBSs is obtained by summing the ratios $\left(N_{\text {simu }} / N_{S U N E}\right)$, see at right of [Fig. 13]. The damage profiles in [Fig. 13] are the damage accumulation in the TBSs of the south wall after exposure to 1 year of climatic actions.
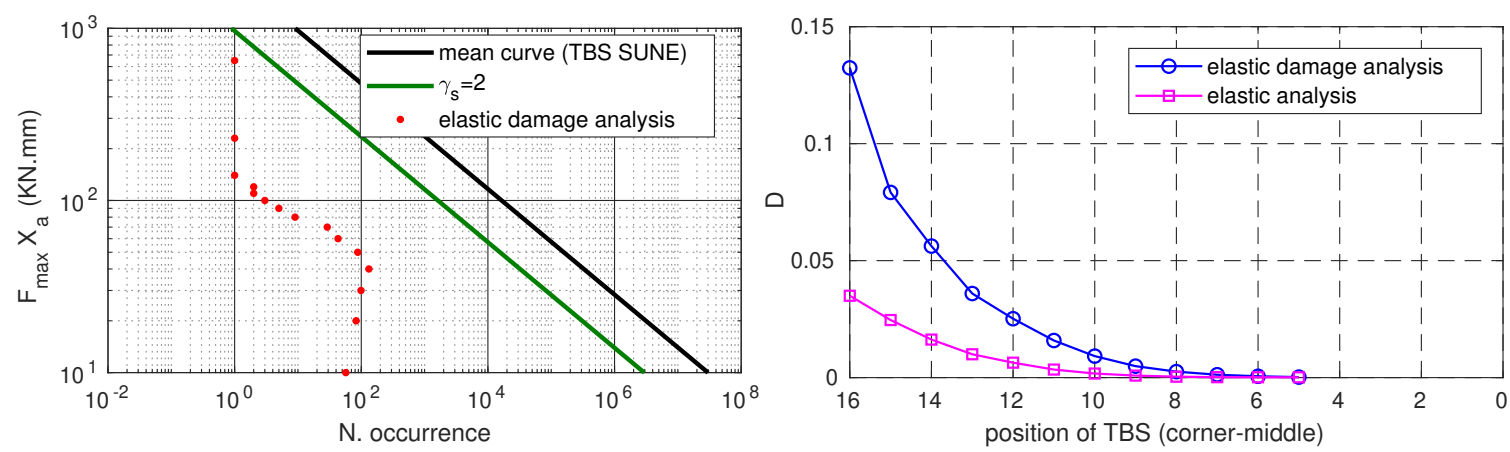

Figure 13: (left): fatigue analysis, (right): damage profile of the TBSs on the south wall

A simplified estimation of the damage accumulation in the TBSs for 50 years of building's life is obtained by multiplying the damage obtained for 1 year with 50, see in [Fig. 14]. First, the TBSs on the west wall are not concerned by this effect, whereas for the TBSs on the south, there are 4 TBSs are fully damaged with elastic damage analysis and 2 for the elastic analysis.
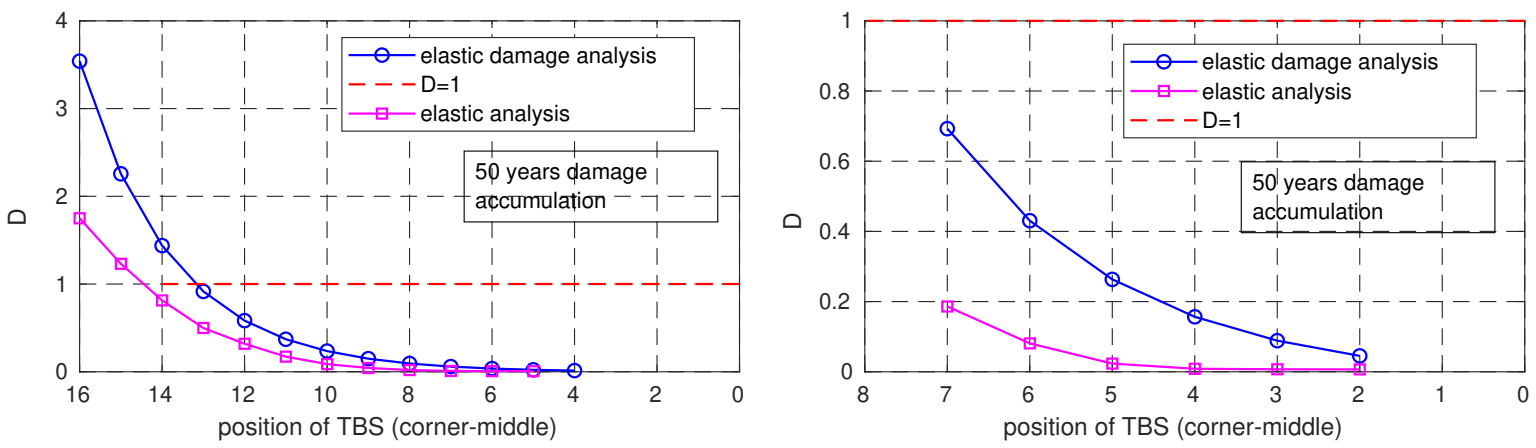

Figure 14: damage accumulation in the TBSs for 50 years: (left) south, (right) west 


\section{CONCLUSION}

In this paper, the effect of climatic actions on the buildings with internal insulation and TBSs at the wall-slab connection has been investigated. A number of algorithms that include shrinkage, creep, damage elasticity and elasto-plasticity models are implanted into the finite element code of Castem [8]. The double complexities in terms of the non linear behaviors and numerical modeling at building scale have limited the model to only a quarter of a building storey. The first simulation with elastic behavior for the concrete has indicated that the walls experience with large tensile stresses, as well as, the TBSs at the corner absorb important horizontal shear. For these considerations, the simulation has to take into account the cracking in concrete in order to obtain more realistic internal forces in the TBSs. For the non linear simulation, the concrete has been changed to elastic damage behavior. Several types of cracking pattern in the walls are presented, which are crack propagation on the surface, vertical cracks and cracking in concrete elements surrounding the TBSs. The crackings in the walls also indicate the insufficiency of minimum reinforcement percentage. An mentioned, important displacement jumps, which generate significant horizontal shear in the TBSs, are noticed. Furthermore, the TBSs experience with repeated yielding for many cycles under the dilatation and contraction effect of the walls. For this reason, the fatigue analysis is made for the TBSs. Even though, the fatigue strength is not really corresponding to the TBS used for slab-wall connection, but the numbers and the order of magnitude of damage in the TBSs are significant. In addition, crackings in the walls have taken part to aggravate the damage in the TBSs. However, the severity of those conclusions must be attached with the following consideration. In the current model, the walls are supposed as blind, then it might overestimates thermal effect compared to a building with openings. Moreover, the extrapolation of the damages in the TBSs from 1 year to 50 years is not correct, as first crackings that create an important damage happens only once in the building.

\section{REFERENCES}

[1] F. Meftah, J. M. Torrenti, and F. Benboudjema, "An elasto-plastic damage approach for the modeling of concrete submitted to mechanical induced effects of drying shrinkage," Rilem Publications.

[2] Y. Xi, Z. P. Bažant, L. Molina, and H. M. Jennings, "Moisture diffusion in cementitious materials moisture capacity and diffusivity," Advanced Cement Based Materials, vol. 1, pp. 258 - 266, 1994.

[3] A. A.M. and W. F.H., "Shrinkage as influenced by strain softening and crack formation, creep and shrinkage of concrete, londres," pp. 103 - 113, 1993.

[4] M. Jirasek and Z. P. Bažant, Inelastic analysis of structures. JOHN WILEY \& SONS, LTD, 2001.

[5] J. Mazars, F. Hamon, and S. Grange, "A new 3d damage model for concrete under monotonic, cyclic and dynamic loadings," Materials and Structures, vol. 48, pp. 3779-3793, Nov 2015.

[6] M. Ryś, "Constitutive modelling and identification of parameters of 3161 stainless steel at cryogenic temperatures," Acta Mechanica et Automatica, vol. 8, no. 3, pp. 136 - 140, 2014.

[7] P. Heng, B. Le Gac, P. Keo, H. Somja, and F. Palas, "Reliability-Based Analysis for Thermal Break System under Low-Cycle Climatic Fatigue Loads," Journal of Structural Engineering, Mar. 2019.

[8] CASTEM, "Code de calcule aux eléments finis cast3m," tech. rep., Commissariat à l'Energie Atomique, CEA-DRN/DMT/SEMT.

[9] M. FRANCE, "https://donneespubliques.meteofrance.fr/.".

[10] N. E. 1991-1-5/NA, "Eurocode 1: Actions on structures - part 1-5: Gernal actions - thermal actions," tech. rep., norme français, 2003.

[11] G. L. Bloa, H. Somja, F. Palas, and M. Hjiaj, "Comportement sismique d'une connexion hybride acier-béton utilisée comme rupteur de ponts thermiques," in 9ème colloque National, AFPS. 